\section{Collaborative working practices in special schools}

\author{
Gill Taylor \\ Class Teacher
}

Sue Dobson

Speech and Language Therapist

\section{Les Staves}

Headteacher

Meads C.E. Primary School, Eastbourne

Teachers of children with severe learning disability have found that the National Curriculum has emphasised how communication affects all the subject areas (Aherne et al., 1990; Ashdown, Carpenter and Bovair, 1991). This has resulted in positive practices developing between education and health professionals. They have found it necessary to work more closely together. For the teacher and a speech and language therapist in one school for children with severe learning disabilities this led to the modification of previously existing methods of working (Grove, 1990). This was particularly important as all National Curriculum areas put emphasis on communication, so the involvement of a speech and language therapist is desirable in all the curriculum subject areas not just for spoken English (Van Oosterom, 1991).

Prior to the introduction of the National Curriculum, the speech and language therapist worked to a medical model. She had a room and withdrew individual children for treatment. She briefly discussed the child's progress in the classroom whilst the teacher supervised the other children in the class. This was less than satisfactory for all the professionals involved. The children's progress was slow, in many cases behaviour problems interfered with the learning process and the skills learnt individually were generalised in to classroom interactions.

The immediate affect of the introduction of the National Curriculum, was that the teacher invited the speech and language therapist to share in the activity of assessing the children with the 'Profiles of Development' (Webster and

(C) 1993,1999. The Down Syndrome Educational Trust Down Syndrome Research and Practice

1993, 1 (2) 84-86
Webster, 1992), which is a developmental curriculum dovetailed into the National Curriculum. The children's individual goals were then included in a team teaching plan where the speech and language therapist worked in the classroom with the teacher.

One particular reception class had six children aged from 5 years to 9 years old, with a wide range of physical, behavioural and emotional abilities. Two of these children had Down's syndrome. This article intends to highlight the progress they made. The interaction of the various children's disabilities and personalities meant that their communication behaviour varied from one situation to another. Their communication on a one to one basis was often totally different to that in the classroom. It also depended on which class members were present.

The class teacher was supported by a nursery nurse and occasional volunteers. The teacher requested that the speech and language therapist used her allocated time, for these children, within the classroom and joined the class for half an hour three times per week.

The communication lessons were very tightly structured. The children were seated around a table and the adults were positioned deliberately between the children. As part of the lesson, the children were expected to stay seated at the table for a set length of time. Trials had shown that lessons involving real objects were the most successful. In addition, one child was visually impaired and it was planned that every child should be fully involved with all the materials at their own personal level of emerging skills. The lessons were broadly based on a variety of commercial language programmes but not specifically on one model.

The children's existing skills were made a priority in each session. For example, the words that a child was known to use already were combined with work on new vocabulary and particular communication skills. That is the children's strengths were used to enable them to meet their identified needs.

Oliver was 7 years old, academically he was the brightest child in the class but his expressive language development was lagging behind his understanding of language. He understood questions involving a choice of two things and responded to simple sentences referring out of the immediate context. He was using two element sentences, such as 'where mummy', and knew about 50 words, including nouns and verbs. He used questions and commands. However, no formal assessment of his linguistic abilities was possible as he did not respond to formal testing and could not co-operate with the Derbyshire Language Scheme, even at a Rapid Screening Test level. It was apparent that he had a low level of language, which is an unusual pattern of language acquisition.

David was 8 years old and one of the more able class members. His understanding of language was difficult to assess, in context he appeared to know a lot but on assessment without contextual cues, he did not. It was felt that he really only understood very simple sentences at a two word level. His expressive communication was at a similar level but his speech was very unclear. Strangers often over estimated his level of language ability. It was felt his development was following the expected pattern. 
Due to the nature of the behaviour of some of the children in the class, work started at a low base line. There was a very wide range of abilities in the class. Some children did not understand at a single word level and were non communicators, others understood complex sentences and communicated by gesture but did not speak. So, each child's aims were different. One of the aims of the blind child in the class was to hold an object and feel it without throwing it on the floor. Using the same objects, another child's aim was to name the object and describe its functions, but whatever the chosen topic for that term all the children used the same materials in the lesson.

Much emphasis was placed upon the time a child had to wait, until it was their turn within the group. They were expected to be quiet, listen to the other children and anticipate when it was their turn to join in. That is part of the groups aims included in the basic conversational skill of turn taking. In the general class room situation the children were busy, noisy and active. They were usually all involved simultaneously in the class's activities and often all talked at the same time. In the lesson, conversational skills were seen as the prime objective.

The children in the group were also encouraged to interact together. A marked feature of their interaction skills was that they tended to communicate only with the adults in the class and did not spontaneously initiate social interactions with each other.

The language work usually involved a game situation where each child had to talk to another. These game activities included Kim's game, hide and seek and guessing games. This also enabled the children to learn the rules of the games, but also learn the rules of social interaction, conversational rules, as well as learning the rules of language use in different situations, with different people and in different places.

The language aims for each child were individually tailored to the child's needs but all of them were about:

expansion of vocabulary

structuring different sentence forms

rule learning in relation to conversation

peer interaction

appropriate social behaviour

attention skills

In addition, at all times during the lessons we were aware of the National Curriculum programmes of study, as these had to be addressed by law. Although few of these children would attain many of the targets we needed to develop ways of accessing them. By using the Profiles of Development we were able to slot the children into the National Curriculum at their own particular level.

For example, Oliver was working towards Attainment target 1 , level 1 speaking and listening.

a) Participation as speakers and listeners in group activities, including imaginative play.

b) Listen attentively and respond to stories and poems.

c) Respond appropriately to simple instructions given to a teacher.
David was working towards Attainment target 1, level 4 speaking and listening.

a) Give a detailed oral account of any event or something that has been learned in the classroom, or explain with reasons why a particular course of action has been taken.

b) Ask and respond to questions in a range of situations with increased confidence.

c) Take part as speakers and listeners in a group discussion or activity, expressing a personal view and commenting constructively on what is being discussed or experienced. $d$ Participate in a presentation.

After 12 months of working together, because of the success of using the combined skills of both teacher and speech therapist, formal assessment of the children was possible. That is the children's level of attention, concentration and cooperation have improved so much that the children could be assessed using the Derbyshire Language Scheme which was not thought possible at the start of the project. In addition the children were now used to sitting at a table for group work, so a side effect of this style of working was that a learning pattern was established that could be used in other classroom activities and curriculum areas.

Oliver was now using language expressively at the same level as his comprehension, he understood and used 5 information carrying words in a sentence. He used a wide range of communication acts, he gave instructions, made requests, was able to express his opinion and describe things. He also used a wide range of question forms. In addition he could initiate and maintain a conversation for several turns. Oliver's Profile of Development was now at a similar level for all communication functions.

David no longer relied so heavily on contextual cues to understand 4+ information carrying words in a sentence and expressed himself at a similar level. Although his speech remained unclear, he could now produce sentences which could be understood by those who were familiar with his style of speech. Although he could still be easily confused by a new situation or unfamiliar language he had become much more confident about trying to communicate in lots of different situations and with different people.

Both David and Oliver are now working within key stage 1 of the National Curriculum alongside children of their own age in mainstream schools during periods of link work with their local primary schools.

For all pupils with severe learning difficulties the content of the whole curriculum is particularly important. (Carpenter, 1992). It offered us opportunities to meet children's needs using a variety of different approaches. All the National Curriculum subjects, English, Maths, History, Geography, Science, Technology, Music, Physical Education and Art are being experienced by Oliver and David in a flexible and individual way. Level 1 in each of the subjects is within their scope even if they do not eventually achieve all the targets. Because of their increased success in the joint teacher and speech and language therapy sessions, Oliver and David have been able to transfer the skills learnt in that lesson to others.

The Curriculum guidance 9 page 24 states :

"Communication is a major area of the English National 
Curriculum and a cross curricula skill........... English is essential to pupils individual development to help them participate in the wider community and society." (NCC 1992).

It was felt that both these children had made a lot of progress for the period of time that was being monitored, far more than they had made over previous years. The collaboration of the teacher and the speech and language therapist had not only been professionally satisfactory, but it had definitely benefited the children involved. The staff felt much more positive about their work environment, were able to perceive that their work was successful and had gained a great deal of knowledge from each other. A major benefit for them was the mutual support they were able to give to each other. When progress was slow and goals achieved are at minimal levels, it is very easy for staff to self denigrate their own skills, abilities and to become unsure about the validity of their work.

From the experience of these two staff therefore, despite all the questions that have been raised about the introduction of the National Curriculum, the effect of its implementation has been positive. It led to new joint working practices which have benefited both the children and the staff involved.

\section{Head teacher's Comments}

Teachers of pupils with Severe Learning Difficulties often feel dissatisfied when speech therapy is delivered exclusively by withdrawing pupils from the classroom. Too often they perceive themselves as remote from the therapist's work. Even when the therapist devotes valuable time to report back it can be difficult for the two to assimilate each others experience of the child's abilities, since each observes the child in a different context.

1. The withdrawal approach centres on one to one interactions and tends to focus on functional/directive language roles.

2.Classroom interactions demand group skills and offer exposure to a wide range of language roles.

Under these circumstances it is difficult for the therapist to make recommendations which the teacher can interpret as transferable into the melee of classroom interactions. Equally, therapists are frustrated if children who communicate freely in the classroom context become unresponsive when withdrawn for therapy or visa versa.

By bridging a professional divide and working together in the classroom, Gill and Sue were able to share observations and perceptions. It was easier for them to use each others expertise to develop strategies which more effectively extended the influence of the speech and language therapist into the pupil's classroom life.

Like many other special schools for pupils with severe learning difficulties our school approaches National Curriculum delivery through the medium of planned topics. Using 'programmes of study' to provide focus areas for teaching we blend 'attainment targets' with a 'developmental curriculum' to offer experiences to all pupils at appropriate levels.

One would expect collaboration between teacher and therapist to occur during classroom sessions which focus on the 'Speaking and Listening' element of the National Curriculum, indeed in the work described this has been the case. However, at the beginning of this article it was stated that since all National Curriculum areas emphasise communication, the therapist has a valuable contribution to make in all subject areas.

Classroom sessions which focus on Science, Geography etc. offer the opportunity to widen a child's experience of the uses of language. The language which occurs in such subjects reaches beyond the directional role which helps to express control or satisfy the child's immediate needs. These subject areas introduce the roles of information seeking and carrying, they refer to the nature of objects and events, it gives and expects descriptions. Through its 'Referential Role' language helps the user move towards the making of connections, and the development of ideas, it is a prime force in concept development.

Teachers and therapists entering partnership in such curricula areas might then be taking positive steps not only in respect of language development, or the acquisition of knowledge. Together with their respective expertise they might help their pupils spin that web where language and thought interact with each other to grow ever wider and more sophisticated.

\section{Bibliography}

Aherne,P., Thornber,A., Fagg, S. and Sketton,S. (1990) Communication for all. London: David Fulton.

Ashdown,R., Carpenter,B. and Bovair,K. (1991) The Curriculum Challenge: Access to the National Curriculum for Pupils with Learning Difficulties. London: Falmer.

Carpenter, B. (1992) The Whole Curriculum: Meeting the Needs of the Whole Child. In Bovair,K., Carpenter,B. and Upton,G. Special Curricula Needs. London: Fulton.

Grove, N. (1990) Relating the National Curriculum English to Pupils with Severe Learning Difficulties. Speech Therapy in Practice.

Madislover,M. and Knowles,W. (1982)Derbyshire Language Scheme. Derbyshire County Council.

NCC (1992) Curriculum Guidance 9. The National Curriculum and pupils with Severe Learning Difficulties. York: National Curriculum Council.

Van Oosterom,J. (1991) Aspects of English. In Ashdown R, Carpenter B, Bovair K. (Eds) The Curriculum Challenge. London: Falmer.

Webster,A and Webster, V.(1990)Profiles of Development. Bristol: Avec Designs. 